\title{
Studies on the Mechanical Parameters of Denture Base Acrylic Resins
}

\section{DIANA DIACONU-POPA, ANCA VITALARIU', MONICA TATARCIUC*, DRAGOS FRATILA*}

${ }^{1}$ Grigore T. Popa University of Medicine and Pharmacy Iasi, Department of Removable Prosthesis, Oral Implantology and Dental Technology, 16 Universitatii Str., 700115, Iasi, Romania

\begin{abstract}
The acrylic resins are the materials most frequently used for dentures realization, which allow to obtain resistant prosthetic constructions with a suitable aesthetic appearance. Depending on the polymerization mechanism, these resins are classified in self-curing, heat-curing or light-curing materials. In order to obtain a properly cured resin with a good mechanical strength, it is necessary to know the properties of the material, the correct dosage of the components and the strict observance of the curing regime. This article aims to evaluate the mechanical parameters of two main categories of resins frequently used in dental practice for removable dentures realization - heat-curing and self-curing resins. For this purpose, the tensile strength and the fracture strength, the Young's modulus values, the surface roughness were analyzed comparatively. The results demonstrate that, after processing and finishing, both types of resins have similar structures and no significant differences regarding the mechanical behavior are registered.
\end{abstract}

Keywords: self-curing resins, heat-curing resins, full dentures, mechanical parameters

\section{Introduction}

Complete edentulous therapy continues to concern specialists everywhere, being considered as a domain of particular difficulty, because it is not limited to the design and fabrication of a full denture, because it addresses to one of the most complex pathology, generating imbalances of all the elements of the dento-maxillary system [1]. The installation of a full edentation should be seen as the beginning of an involution process of disturbing the physiological balance, generated by the constant depreciation of the anatomical structures of the whole body, with implications on the stomatognathic system, which can trigger permanent stresses, that places the elderly, in a state of psycho-somatic lability $[2,3]$.

An important role in the satisfaction of the patients wearing a removable denture has the realization of a prosthetic construction that adapts perfectly to the oral cavity and completely restores the altered functions; also, a balance being always be strucked between the patient's wishes and the objective possibilities of the clinical situation [4-7].

In order to obtain removable prosthesis that satisfies all these requirements, the material has to be very carefully chosen; the resin must sum up a series of characteristics: to have a color close to the oral tissues and a translucency that allows the optimal reproduction of the physiognomic function, not to change color over time, to present volumetric stability, not to alter its shape during mechanical processing or in the oral environment, to have an elasticity and abrasion resistance adequate to any demands in the oral cavity, to be waterproof for fluids in the oral cavity, to have a smooth and glossy surface, which does not allow the adhesion of food fragments or bacterial plaque and it should be easy to clean; also the material must have a low density, a low thermal conductivity, and it must not undergo volumetric variations during temperature variations.

The materials frequently used for partial and full dentures are acrylic resins, offering these prosthetic constructions sufficient strength and a proper aesthetic appearance [8-12].

This article aims to evaluate the mechanical parameters of two main categories of resins frequently used in dental practice for removable dentures - heat-curing resins (HCR) and self-curing resins (SCR). 


\section{Materials and methods}

In order to analyze the mechanical behavior of these two categories of resins we used two different types of acrylic dental resins: a heat curing (Meliodent HC/ Heraeus Kulzer Senden, Germany)) and a self-curing resin (Vertex Castavaria /Vertex Dental B.V., Yeist, Netherland) We made 60 samples, 30 for each material, that were tested from the mechanical point of view and also we analized the structure and the surface parameters. Pink wax patterns were made, $2 \mathrm{~mm}$ thickness, with $75 \mathrm{~mm}$ length, $12.5 \mathrm{~mm}$ width at the extremities and $4 \mathrm{~mm}$ in thickness in the central area. The wax patterns were transformed in acrylic specimens according to the technology used for acrylic dentures. They were invested in dental stone (Elite Rock class IV/Zhermack) in order to obtain a mold. Then the acrylic resin pastes were prepared, following the producers indications for each type. The powder and liquid were mixed into a porcelain jar, then the acrylic resin paste was packed into the mold at the dough stage, the flask was closed and pressed. For the heat-curing resin the flask was immersed into a water bath and the temperature was rised up to $100^{\circ} \mathrm{C}$, at 2-4 bar, during $20 \mathrm{~min}$, and for self-curing resin reaction conditions have been $45^{\circ} \mathrm{C}, 2-4$ bar, during $5 \mathrm{~min}$. After polymerization the samples were finished, polished and finally immersed in distilled water and stored at $37^{\circ} \mathrm{C}$, for one week, before testing (Figure 1).

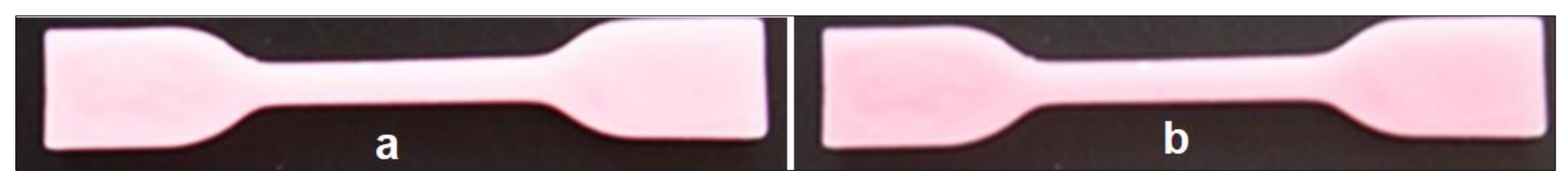

Figure 1. HCR (a) and SCR (b) samples

\subsection{Tests for analyzing surface roughness}

Roughness is an important characteristic of the surface quality and can be assessed by determining the micrometric profile of the finished and polished samples. For each sample $\mathrm{Ra}$ was registered. Ra represents the arithmetical mean of the absolute values of the profile deviations from the mean line of the roughness, and $\mathrm{Rz}$ - the average of all values represented by the maximum height between the maximum and the minimum profile within the assessment length, for each sample. Ra and $\mathrm{Rz}$ values were automatically calculated and the diagrams were recorded with the Mahr M1 Perthometer device (Figure 2).

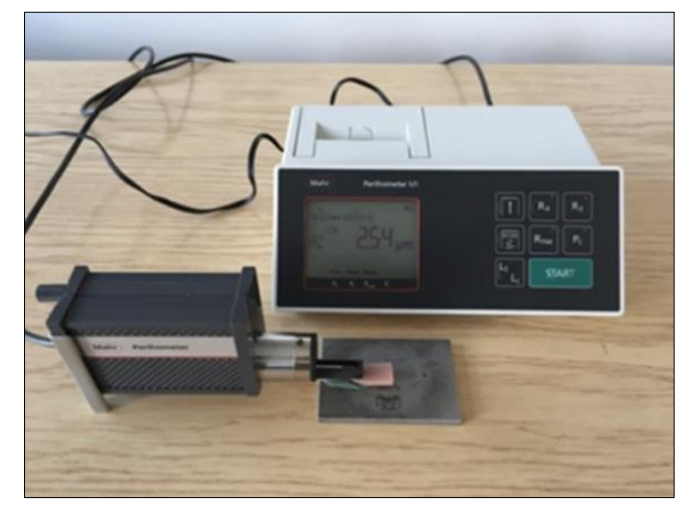

Figure 2. Mahr M1 Perthomete

Mechanical tests were carried out at room temperature according to the ISO 527-1: 2000 standard, using a computer-controlled testing machine (Instron 3382) equipped with a dynamic clip-on strain gauge extensometer (Instron 2620-601) for direct strain measurement. The rectangular specimens were placed and fixed between the grips of the testing machine and the tensile load was applied at a crosshead speed of $1 \mathrm{~mm} / \mathrm{s}$. Young's modulus, tensile yield stress and tensile strength were determined. 


\section{Results and discussions}

The shape and dimensions of the micrometric profile have an influence on the adherence and development of the bacterial biofilm at the internal surfaces of the acrylic prostheses. After analyzing the roughness, the results do not show changes in the surfaces of the samples: HCR and SCR, the specimens being processed with the same instrumentation and in the same steps (Figure 3).

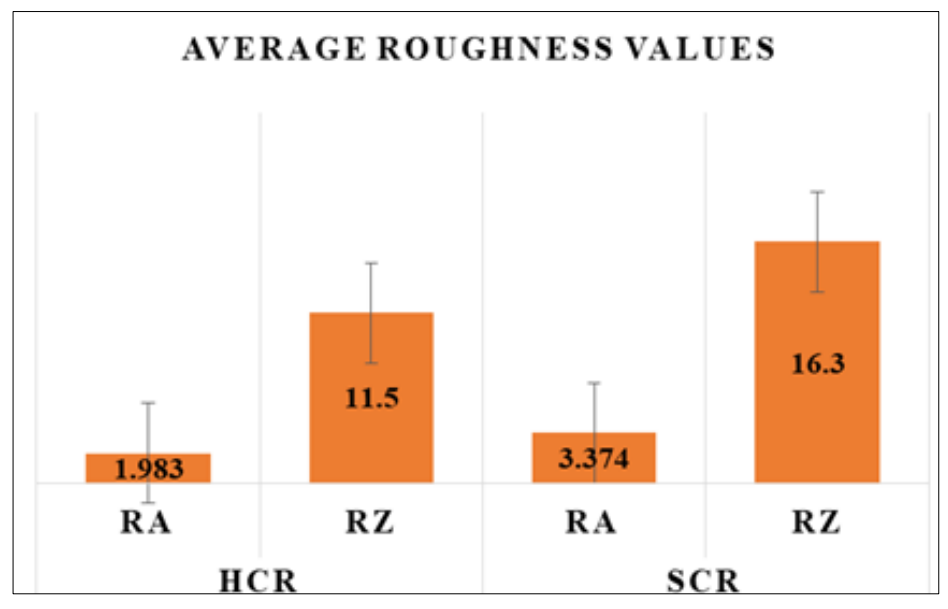

Figure 3. The roughness values registered on the resin surfaces

The charts obtained after centralization the results, for both categories of resins, are not significantly different, at this stage the roughness of the surfaces being very similar. If the finishing and polishing methods were the same, the minimum difference that appears between the two values is determined by the curing mechanism.

Young's modulus (E), was calculated according to the Hook's law $E=\sigma / \varepsilon$, as the ratio between stress (б) and deformation $(\varepsilon)$. At a constant pressure, the decreasing of Young's modulus demonstrates a more important deformation; the lower the Young's modulus, the greater the flexibility of the material, for total prostheses being not considered an advantage. The results were statistically processed by the method of two-way ANOVA dispersive analysis and statistical significance was set at $\mathrm{p}<0.05$.

Analyzing the data obtained for the Young's modulus, calculated for both categories of resins, no significant differences were observed (Figure 4).

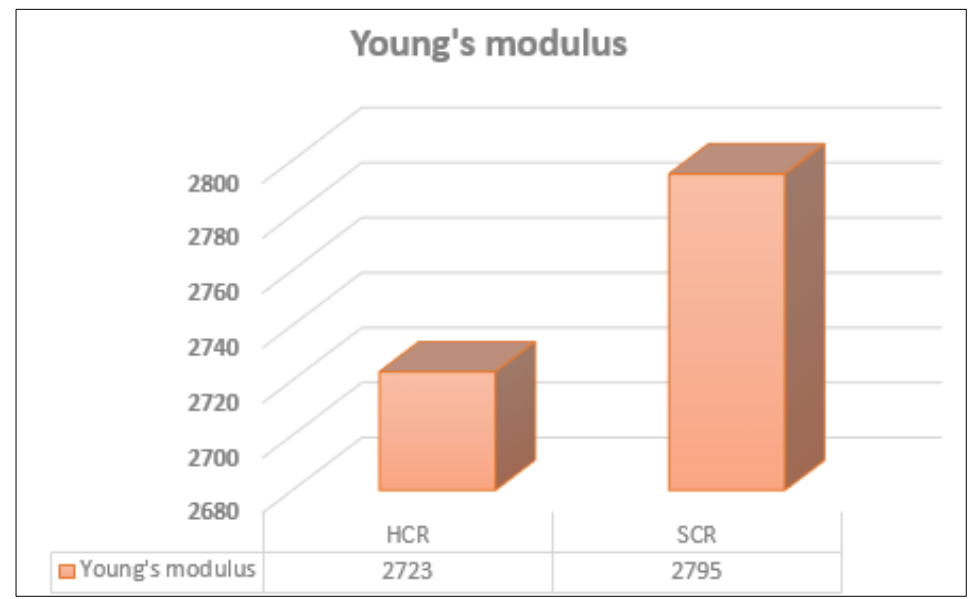

Figure 4. Young's modulus values (MPa)

The diagrams for tensile stress and fracture strength show that, when the load is applied to the samples, it will cause changes of shape; the very first step being the elastic deformation, which is a temporary shape change, self-reversing after the force is removed. If the action of the force continues, 
this change is followed by a plastic deformation and, finally by the fracture of the samples, which consists in to the separation of the material into pieces by an imposed stress (Figure 5).

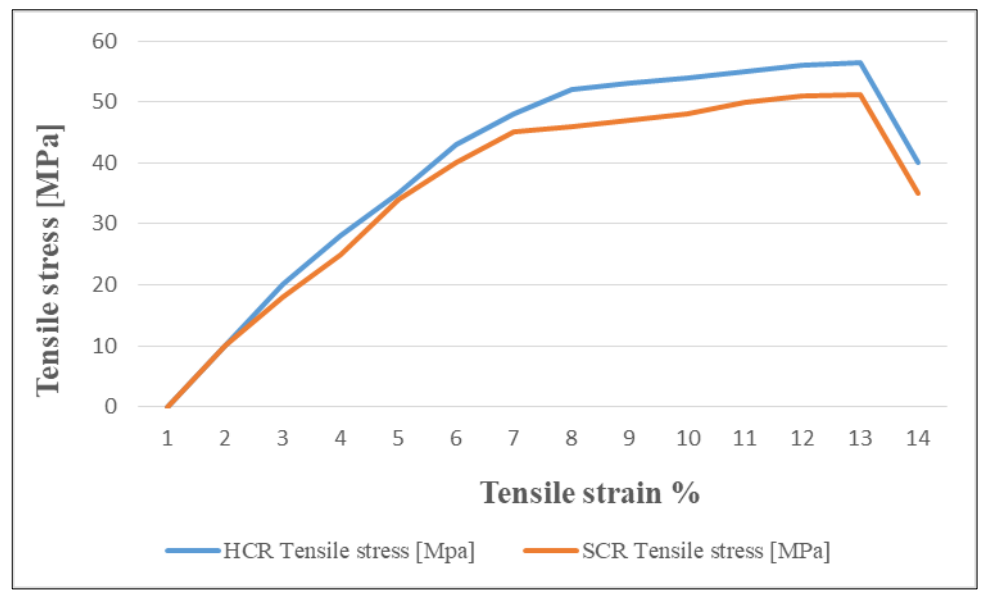

Figure 5. Tensile tests diagrams

The maximum value for tensile stress is $44 \mathrm{MPa}$ for HCR and $42 \mathrm{MPa}$ for SCR (Figure 6).

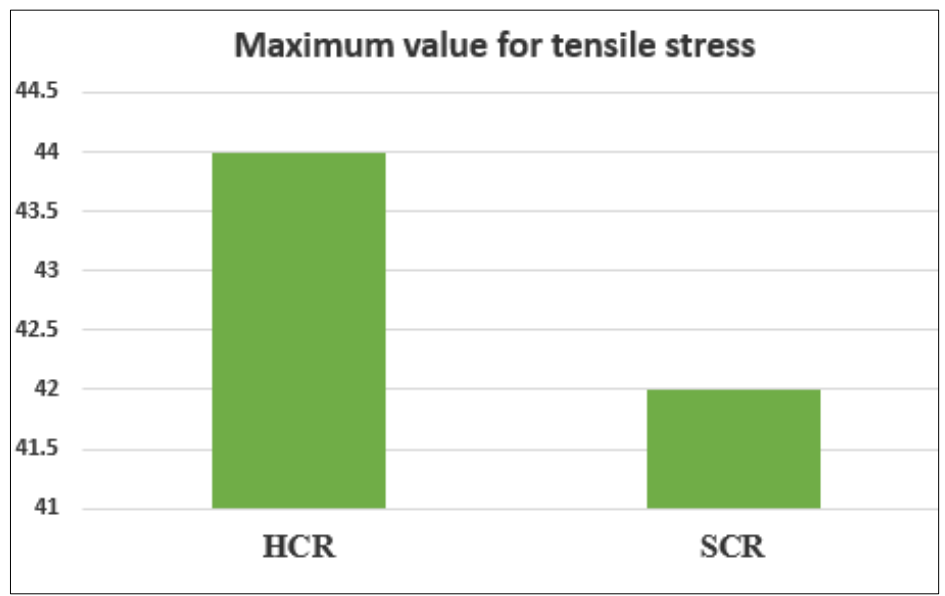

Figure 6. Maximum value for tensile stress (MPa)

The ultimate tensile strength value for HCR is $56.4 \mathrm{MPa}$ and for SCR is 51.2 MPa (Figure 7).

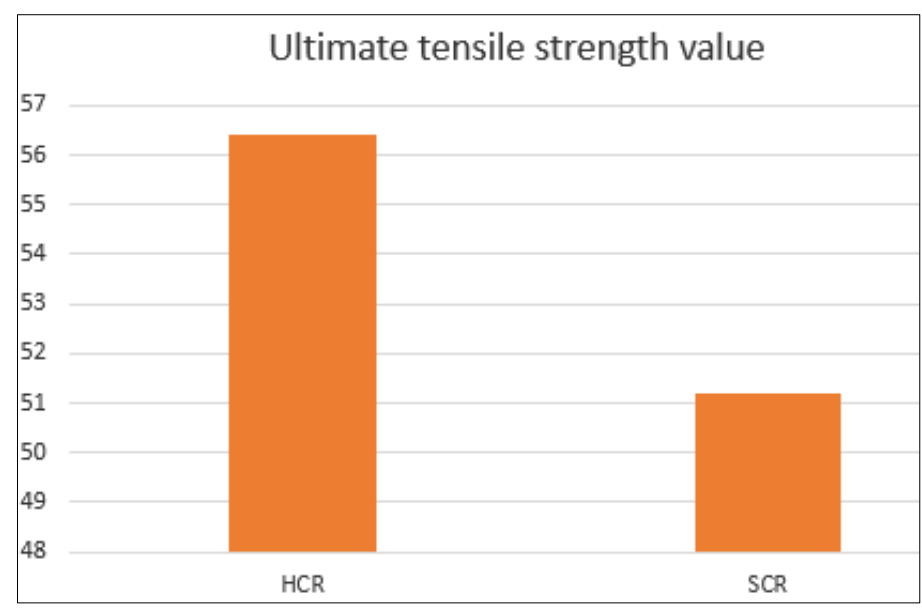

Figure 7. Ultimate tensile strength value (MPa) 
The very small differences between these values show that the resins have a similar behavior at tensile forces.

Testing the mechanical properties of the denture base resins it is an important issue. Flexural strength is useful in order to compare denture base materials because it reflects the complex stresses applied to the denture during mastication and it indicates the materials' rigidity $[9,10]$.

Also, the surface state has a major impact on the patient's comfort and the prevention of inflammation in the oral mucosa [11]. The homogeneous structure of the material, without porosity ensures to the future prosthesis, longevity, resistance and longevity over time [12]. Our results notice that no significant differences between the mechanical properties of the two denture base materials are registered.

\section{Conclusions}

Within the limitations of this study, the mechanical properties of acrylic resins were not influenced by the curing method. The acrylic specimens have similar mechanical characteristics and comparable values of surface roughness.

Also, no structural differences were found between both categories of resins. So we can notice that, at least in the initial stage, the acrylic samples of HCR and SCR do not show significant differences and have a similar mechanical behavior.

Since this research was limited to samples analyzed immediately after processing and finishing, further studies are necessary to evaluate the mechanical properties after a longer period of time, in which these materials have been functionally required in the oral cavity.

\section{References}

1.POWELL, S.K., CRUZ, R.L.J., ROSS, M.T., WOODRUFF, M.A., Past, Present, and Future of SoftTissue Prosthetics: Advanced Polymers and Advanced Manufacturing, Adv. Mater, 32(42), 2020, Article Number: 2001122, DOI: 10.1002/adma.202001122.

2.TATARCIUC M., VITALARIU A., DIACONU-POPA D., Follow Up of The Patients with Removable Partial Dentures-Technological Aspects, Rom. J. Med. Dent. Educ., 8, no. 5, 2019, p. 6-11. 3.BORTUN C.M. CERNESCU A., ARDELEAN L., Mechanical Properties of Some Dental Resins in Wet and Dry Conditions, Mater. Plast., 49(1), 2012, 5-8.

4.NAIK, A.V., Complete denture fractures: A clinical study, J. Indian Prosthodont., 9(3), 2009, p. 148150.

5.BOHRA, P.K., GANESH, P.R., REDDY, M.M., EBENEZAR, A.V.R., SIVAKUMAR. G., Colour stability of heat and cold cure acrylic resins, J. Clin. Dent. Res., 9, 2015, p.12-15.

6.GHIBAN, N., BORTUN, C.M, BORDEASU, I., GHIBAN, B., FAUR, N., CERNESCU, A., HANGANU S.C., Evaluation of Mechanical Properties by Stereo-and Scanning Electron Microscopy of Some Heat Curing Dental Resins, Mater. Plast., 47(2), 2010, 240-243.

7.GAD, M., FOUDA, S.M., AL-HARBI, F.A., NÄPÄNKANGAS, R., RAUSTIA A., PMMA denture base material enhancement: a review of fiber, filler, and nanofiller addition, Int. J. Nanomed., 12, 2017, p. 3801-3812, DOI https://doi.org/10.2147/IJN.S130722.

8.CERVINO, G., CICCIU, M., HERFORD, A.S., GERMANA, A., FIORILLO, L., Biological and Chemo-Physical Features of Denture Resins, Materials, 13(15), 2020, Article Number: 3350, DOI: 10.3390/ma13153350.

9.PRPIC, V., SCHAUPERL, Z., CATIC, A., DULCIC, N., CIMIC, S., Comparison of Mechanical Properties of 3D-Printed, CAD/CAM, and Conventional Denture Base Materials, J. Prosthodont., 29(6), 2020, pp. 524-528, DOI: 10.1111/jopr.13175.

10.CHOI, J.J.E., UY, C.E. RAMANI, R.S., WADDELL, J.N., Evaluation of surface roughness, hardness and elastic modulus of nanoparticle containing light-polymerized denture glaze materials, J. Mech. Behav. Biomed., 103, 2020, Article Number: UNSP 103601, DOI: 10.1016/j.jmbbm.2019.103601 
11.ABDULRAZZAQ NAJI, S.A; JAFARZADEH KASHI, T.B., BEHROOZIBAKHSH, M.C., HAJIZAMANI H.D., HABIBZADEH S., Recent Advances and Future Perspectives for Reinforcement of Poly(methyl methacrylate) Denture Base Materials: A Literature Review Journal of Dental Biomaterials, J. Dent. (Shiraz), 5(1), 2018, p.2-14

12.VITALARIU, A.M., LAZAR, L., BURUIANA, T., DIACONU, D., TATARCIUC, M.S., Studiu privind starea de suprafaţă a răşinilor acrilice in raport cu metodele de prelucrare mecanică, Rev. Med. Chir. Soc. Med. Nat. Iasi, 115(2), 2011, p.542-547, ISSN: 2066-6063,

http://www.revmedchir.ro/22011.html

$\overline{\text { Manuscript received: } 05.11 .2020}$ 